\title{
Evolutionary Triangulation to Refine Genetic Association Studies of Spontaneous Preterm Birth
}

\author{
Tracy A. Manuck, MD, MSCl ${ }^{1}$ Minjun Huang, $\mathrm{MS}^{2} \quad$ Louis Muglia, MD ${ }^{3} \quad$ Scott M. Williams, $\mathrm{PhD}^{4}$ \\ ${ }^{1}$ Department of Obstetrics \& Gynecology, University of North \\ Carolina at Chapel Hill, Chapel Hill, North Carolina \\ 2 Department of Molecular and Systems Biology, Dartmouth College, \\ Hanover, New Hampshire \\ 3 Department of Pediatrics, Cincinnati Children's Hospital, \\ Address for correspondence Tracy A. Manuck, MD, MSCl, Division of \\ Maternal-Fetal Medicine, Department of Obstetrics \& Gynecology, \\ University of North Carolina at Chapel Hill, 3010 Old Clinic Building, \\ CB\#7516, Chapel Hill, NC 27599-7516 \\ (e-mail: tmanuck@med.unc.edu).
} Cincinnati, Ohio

${ }^{4}$ Department of Epidemiology and Biostatistics, Case Western

Reserve University, Cleveland, Ohio

Am J Perinatol 2017;34:1041-1047.

\section{Abstract \\ Keywords \\ - preterm birth \\ - evolutionary triangulation \\ - genetic \\ - susceptibility \\ - racial disparity}

Objective The objective of this study was to apply evolutionary triangulation, a novel technique exploiting evolutionary differentiation among three populations with variable disease prevalence, to spontaneous preterm birth (PTB) genetic association studies.

Study Design Single nucleotide polymorphism (SNP) allele frequency data were obtained from HapMap for CEU, GIH/MEX, and YRI/ASW populations. Evolutionary triangulation SNPs, then genes, were selected according to the overlaps of genetic population differences ( $\mathrm{CEU}=$ outlier). Evolutionary triangulation genes were then compared with three PTB gene lists: (1) top maternal and fetal genes from a large genome-wide association study of PTB, (2) 640 genes from the database for PTB, and (3) 118 genes from a recent systematic review. Empirical $p$-values were calculated to determine whether evolutionary triangulation enriched for putative PTB associating genes compared with randomly selected sample genes.

Results Evolutionary triangulation identified $5 / 17$ maternal genes and $8 / 16$ fetal genes from PTB gene list 1. From list 2, 79/640 were identified by CEU_GIH_YRI evolutionary triangulation, and $57 / 640$ were identified by CEU_ASW_MEX evolutionary triangulation. Finally, 20/118 genes were identified by evolutionary triangulation from gene list 3 . For all analyses, $p<0.001$ except CEU_ASW_MEX analysis of list 3 where $p=0.002$.

Conclusion Genes identified in prior PTB association studies confirmed by evolutionary triangulation should be prioritized for further genetic prematurity research.
Preterm birth (PTB) remains a major public health problem worldwide, ${ }^{1}$ and is the leading cause of neonatal morbidity and mortality of nonanomalous infants in the United States., ${ }^{2,3}$ Approximately two-thirds of PTB are spontaneous, and though there appears to be a genetic component to spontaneous PTB susceptibility, genetic association studies have traditionally yielded inconsistent results and have been difficult to replicate. Spontaneous PTB is known to vary by population, and significant differences are seen in PTB rates across the world.
Though sociodemographic factors can account for some of the differences in spontaneous PTB rates, it cannot account for all differences. Variations in rates of prematurity by population are also seen within countries, including the United States, where disparities are pronounced. Non-Hispanic black women have a rate of spontaneous PTB that is $49 \%$ higher than nonHispanic white women. ${ }^{3,4}$ Hispanic women also have an elevated rate of spontaneous PTB compared with non-Hispanic white women. accepted

April 20, 2017

published online

May 22, 2017
Copyright @ 2017 by Thieme Medical Publishers, Inc., 333 Seventh Avenue, New York, NY 10001, USA. Tel: +1(212) 584-4662.
DOI https://doi.org/ 10.1055/s-0037-1603508. ISSN $0735-1631$. 
Genetic variation (e.g., allele frequencies at specific single nucleotide polymorphisms [SNPs]) is known to be population specific. All populations have unique genetic variation inherent to each group. For example, in general, non-Hispanic black populations are known to have more variation and many more low-frequency variation compared with other populations. Across the genome, though some regions are highly conserved with minimal variations between individual and between populations, at other sites, minor allele frequencies have the potential to vary between individuals and between populations.

Evolutionary triangulation is a novel genetic filtering and prioritization method that capitalizes on the differences in allele frequencies between populations to refine results from genetic association studies. ${ }^{5}$ The technique identifies alleles that differ among populations with different disease prevalence, such as spontaneous PTB. It has previously successfully identified genes implicated in lactose intolerance, Smith-Lemli-Opitz, and albinism. ${ }^{5}$

We hypothesized that genes identified by evolutionary triangulation could refine results from previous spontaneous PTB gene association studies.

\section{Materials and Methods}

First, we generated our evolutionary triangulation gene lists. We obtained baseline SNP allele frequency data for populations selected to represent non-Hispanic black, non-Hispanic white, and Hispanic women using data from the International Haplotype Map Project HapMap ${ }^{6,7}$ ( - Table 1). Each population was chosen based on population differences in rates of PTB. HapMap is an international consortium with publically available SNP frequencies, genotypes, and haplotypes by population, and can be applied to estimate genetic ancestry. ${ }^{7-9}$ Next, to assess population differences, we calculated Wright's fixation index $\left(\mathrm{F}_{\mathrm{ST}}\right),{ }^{10,11}$ a metric assessing population genetic differences by pairwise allele comparisons between groups, according to the Cockerham and Weir's formula. ${ }^{12}$ We first compared alleles between the first two populations, and then compared the allelic differences between populations 1 and 3. Finally, we compared differences between populations 2 and 3. A list of evolutionary triangulation SNPs was then generated according to the overlaps of low $\mathrm{F}_{\mathrm{ST}}$ between the populations with similarly high rates of spontaneous PTB (YRI, GIH, MEX, and ASW) and high $\mathrm{F}_{\mathrm{ST}}$ with CEU as the outlier population with lower rates of spontaneous PTB. We used several thresholds of high and low $\mathrm{F}_{\mathrm{ST}}$, that is, several degrees of differentiation. Each evolutionary triangulation SNP was then used to identify nearby genes as evolutionary triangulation genes, as recent literature suggests that variants in the regulatory regions or near transcription start sites of genes may impact function and possibly disease. For that reason, genes located within $100 \mathrm{~kb}$ of each evolutionary triangulation SNP were compiled to comprise the final evolutionary triangulation gene list. This methodology is summarized in - Fig. 1. We generated two separate evolutionary triangulation SNP lists, each containing a representative non-Hispanic white, Hispanic, and non-Hispanic black populations: (1) CEU_GIH_YRI and (2) CEU_MEX_ASW.

Next, we compared the evolutionary triangulation gene lists generated earlier to three separate gene lists. Spontaneous PTB gene list 1 comprised the top 20 maternal and fetal SNPs from a multicenter genome-wide association study of 1,025 spontaneous PTB cases delivering less than 34 weeks' gestation and 1,015 matched term controls with spontaneous labor; these top 20 SNPs were located in 32 different genes. ${ }^{13}$ Spontaneous PTB gene list 2 consisted of 640 genes on the online database for PTB "dbPTB" Web site (www. ptbdb.cs.brown.edu). ${ }^{14,15}$ This Web site, hosted by Brown University, provides a web-based aggregation site of published genes previously associated with spontaneous PTB in one or more studies. ${ }^{14,15}$ Our third spontaneous PTB gene list comprised the 118 candidate genes identified from a recent systematic review of 92 genetic studies of spontaneous PTB published from 2007 to 2015 . $^{16}$

Finally, we applied principles of evolutionary triangulation to each gene list. Genes found in both our evolutionary triangulation gene list and the spontaneous PTB gene lists were considered top candidate genes, and were examined for evidence of expression in the myometrium or placenta. We also analyzed genes identified by evolutionary triangulation using the STRING database (http://string-db.org) ${ }^{17}$ to assess functional relationships, interactions between genes, and to classify genes into ontology groups as applicable.

Permutation testing was performed to determine whether evolutionary triangulation significantly enriched in the lists of genes associated with spontaneous PTB. Specifically, this was performed by calculating empirical $p$-values, comparing the ability of evolutionary triangulation to detect putative spontaneous PTB-associated genes from a list of randomly sample genes. We first generated a null (random) list of genes by sampling from the list of genes in the entire genome 10,000 times. For each resample, we

Table 1 Selected populations used to generate evolutionary triangulation gene lists

\begin{tabular}{|l|l|l|}
\hline Population & Source from HapMap & Representative population \\
\hline CEU & Utah residents with European ancestry & Non-Hispanic white \\
\hline GIH & Gujarati Indians (Houston, TX) & Hispanic \\
\hline MEX & Mexican ancestry (Los Angeles, CA) & Hispanic \\
\hline YRI & Yoruba (Ibadan, Nigeria) & Non-Hispanic black \\
\hline ASW & African ancestry in southwestern United States & Non-Hispanic black \\
\hline
\end{tabular}




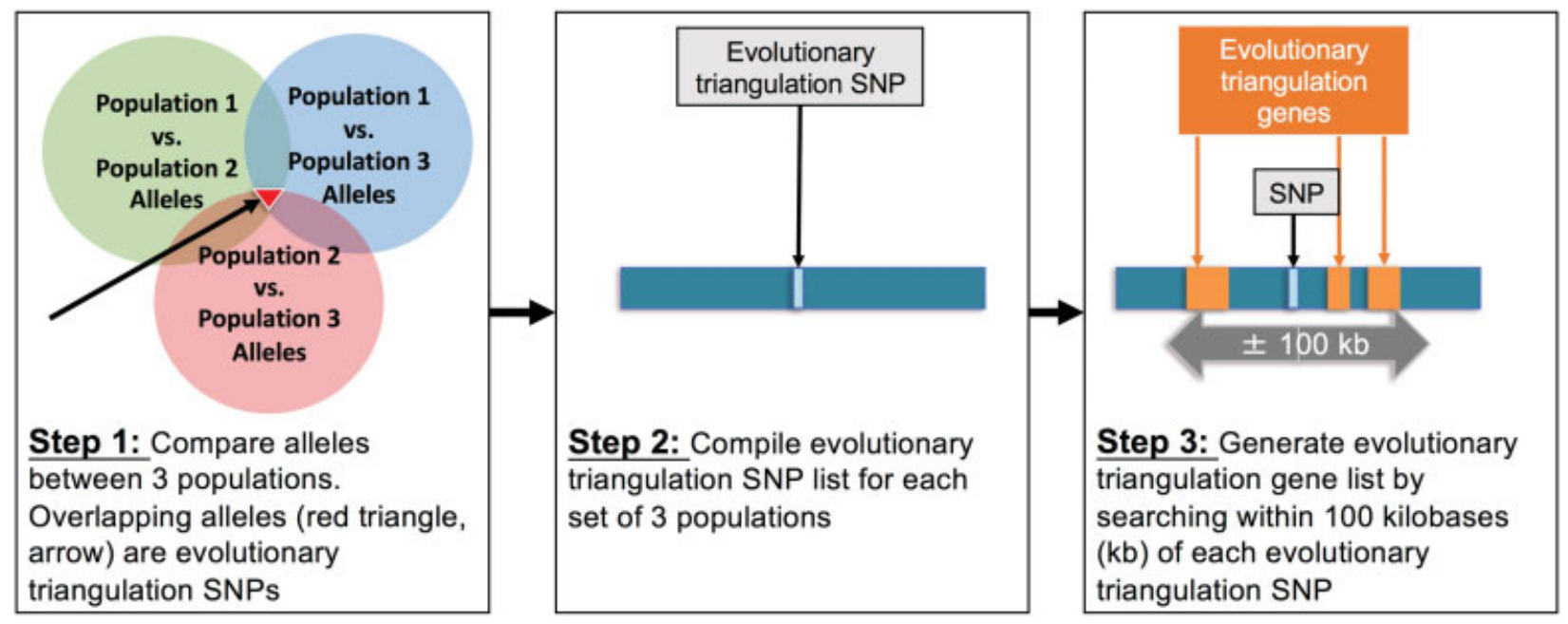

Fig. 1 Summary of evolutionary triangulation methodology. SNP, single nucleotide polymorphism.

randomly selected the number of genes corresponding to each of the three gene lists (32, 640, and 118, respectively). We then counted the number of genes from each resampling that appeared in each of the three lists. From these counts, we generated three null distribution lists of spontaneous PTB genes. Empirical $p$-values were calculated by dividing the number of counts that exceed evolutionary triangulation detected PTB genes in CEU_GIH_YRI and CEU_MEX_ASW separately and CEU_GIH_YRI and CEU_MEX_ASW combined.

\section{Results}

We examined both maternal and fetal SNPs distributed in 32 different genes from the large genome-wide association study of early spontaneous PTB (PTB gene list 1). Multiple top genes in the genome-wide association study were confirmed by evolutionary triangulation filtering methods, using both evolutionary triangulation population gene lists. In total, 13 of the 32 genes were identified using evolutionary triangulation. The enrichment for spontaneous PTB genes from list 1 was significant (empiric $p<0.0001$ for CEU_GIH_YRI; $p<0.0001$ for CEU_MEX_ASW; $p<0.0001$ for combined CEU_GIH_YRI and CEU_MEX_ASW). These results included three maternal genes expressed in the myometrium [myopalladin [MYPN], ethanolamine kinase 1 [ETNK1], contactin 5 [CNTN5]) as well as six fetal genes expressed in the placenta (ribonuclease T2 [RNASET2], SMAD family member 9 [SMAD9], ras responsive element-binding protein 1 [RREB1], sortilinrelated receptor 1 [SORL1], potassium voltage-gated channel subfamily $\mathrm{H}$ member 7 [KCNH7], and nucleolar protein 10 [NOL10]), - Table 2. These nine significant genes were not overrepresented in any gene ontology (GO) groups and no functional enrichment was appreciated.

We then evaluated PTB gene list 2, the 640 genes listed in the online dbPTB. In total, evolutionary triangulation identified 123 unique genes from the online dbPTB; $19 \%$ overall. This number represented significant enrichment as compared with random sampling of the genome (empiric $p<0.0001$ for
CEU_GIH_YRI; $p<0.0001$ for CEU_MEX_ASW; $p<0.0001$ for combined CEU_GIH_YRI and CEU_MEX_ASW). Overall, the CEU_GIH_YRI evolutionary triangulation gene list identified a higher proportion of genes from the online $\mathrm{dbPTB}(77 /$ 640,12.0\%) compared with the CEU_ASW_MEX list (55/640, $8.6 \%$ ). These 123 genes were analyzed by STRING for evidence of biologic pathway enrichment. Notably, 44 genes were implicated in response to stress pathways (G0:0006950), 25 genes in immune response (GO:006955), 20 in innate immunity (GO:0045087), and 17 in positive regulation of the immune system process pathways (GO:0002684). Eleven genes from the online dbPTB were identified by both the CEU_GIH_YRI and the CEU_ASW_MEX list; their names and previous associations with PTB and other pregnancy complications are shown in - Table 3. From these top 11 genes identified in both evolutionary triangulation lists, functional enrichments were found within receptor signaling protein (GO:0005057; kinase insert domain receptor [KDR], anaplastic lymphoma receptor tyrosine kinase $[A L K]$, interleukin 1 receptor-associated kinase 1 [IRAK1]) and nuclear factor-KBinducing kinase activity (GO:0004704; ALK, IRAK1) pathways.

Finally, we found 20/118 candidate genes from spontaneous PTB gene list 3 by evolutionary triangulation (-Table 4). These associations for spontaneous PTB list 3 were also significant (empiric $p<0.001$ for CEU_GIH_YRI; $p=0.002$ for CEU_MEX_ASW; $p<0.001$ for combined CEU_GIH_YRI and CEU_MEX_ASW). Of these, 10 (interleukin 1 receptor type 2 [IL1R2], nitric oxide synthase 2 [NOS2], FMS-related tyrosine kinase 1 [FLT1], interleukin-6 [IL6], $K D R$, colony-stimulating factor 2 [CSF2], Sp3 transcription factor [SP3], IRAK1, toll-like receptor 10 [TLR10], protein kinase c $\alpha(P R K C A])$ are genes previously implicated in innate immunity (GO:0002376) or the immune response (G0:0006955). In addition, eight genes (angiotensinogen [AGT], FLT1, nitric oxide synthase 3 [NOS3], PRKCA, IL6, $K D R$, collagen type IV $\propto 3$ chain [COL4A3], and collagen type IV $\alpha 2$ chain [COL4A2]) are involved in the regulation of angiogenesis (GO:00045765). 
1044 Evolutionary Triangulation for Spontaneous Preterm Birth Manuck et al.

Table 2 Genes from PTB gene list 1 confirmed by evolutionary triangulation

\begin{tabular}{|c|c|c|c|c|c|c|}
\hline \multirow[t]{2}{*}{ Gene } & \multirow[t]{2}{*}{ Chr. } & \multirow[t]{2}{*}{ Gene description } & \multicolumn{2}{|c|}{$\begin{array}{l}\text { Originally published } \\
\text { findings }\end{array}$} & \multicolumn{2}{|c|}{ Evolutionary triangulation list } \\
\hline & & & Location & $p$-Value & CEU, GIH, YRI & CEU, ASW, MEX \\
\hline SHROOM3 & 4 & Shroom family member 3 & Maternal & $5.6 \mathrm{e}^{-6}$ & Yes & No \\
\hline LOC100128865 & 4 & Methyltransferase like 5 & Maternal & $2.7 e^{-5}$ & Yes & Yes \\
\hline MYPN & 10 & Myopalladin & Maternal & $3.3 \mathrm{e}^{-5}$ & Yes & No \\
\hline ETNK1 & 12 & Ethanolamine kinase 1 & Maternal & $3.7 e^{-5}$ & Yes & No \\
\hline CNTN5 & 11 & Contactin 5 & Maternal & $4.1 e^{-5}$ & Yes & No \\
\hline LOC100128365 & 6 & Interferon-stimulated exonuclease & Fetal & $2.7 \mathrm{e}^{-12}$ & Yes & No \\
\hline RNASET2 & 6 & Ribonuclease T2 & Fetal & $1.4 \mathrm{e}^{-10}$ & No & Yes \\
\hline L3MBTL3 & 6 & $\begin{array}{l}\text { Lethal(3) malignant brain } \\
\text { tumor-like protein } 3\end{array}$ & Fetal & $8.3 \mathrm{e}^{-7}$ & Yes & No \\
\hline SMAD9 & 13 & SMAD family member 9 & Fetal & $1.1 \mathrm{e}^{-6}$ & No & Yes \\
\hline RREB1 & 6 & $\begin{array}{l}\text { Ras responsive element-binding } \\
\text { protein } 1\end{array}$ & Fetal & $2.3 \mathrm{e}^{-6}$ & Yes & No \\
\hline SORL 1 & 11 & Sortilin-related receptor 1 & Fetal & $2.8 \mathrm{e}^{-6}$ & Yes & No \\
\hline KCNH7 & 2 & $\begin{array}{l}\text { Potassium voltage gated channel } \\
\text { subfamily } \mathrm{H} \text { member } 7\end{array}$ & Fetal & $6.2 \mathrm{e}^{-6}$ & No & Yes \\
\hline NOL10 & 2 & Nucleolar protein 10 & Fetal & $6.4 e^{-6}$ & Yes & No \\
\hline
\end{tabular}

Abbreviations: Chr, chromosome; PTB, preterm birth.

Table 3 Genes from PTB list 2 (dbPTB) identified by both CEU_GIH_YRI and CEU_ASW_MEX evolutionary triangulation lists

\begin{tabular}{|c|c|c|c|}
\hline Gene & Chr. & Gene description & $\begin{array}{l}\text { Prior association(s) with PTB and other adverse } \\
\text { pregnancy outcomes }\end{array}$ \\
\hline$A L K$ & 2 & Anaplastic lymphoma receptor tyrosine kinase & $\begin{array}{l}\text { Peripheral blood gene expression in early pregnancy } \\
\text { associated with PTB } 25\end{array}$ \\
\hline CNTLN & 9 & Centlein, centrosomal protein & $\begin{array}{l}\text { Peripheral blood gene expression in early pregnancy } \\
\text { associated with PTB } 25\end{array}$ \\
\hline IRAK1 & $x$ & Interleukin 1 receptor-associated kinase 1 & Increased in response to intrauterine inflammation ${ }^{26}$ \\
\hline KCNK2 & 1 & Potassium channel, subfamily $\mathrm{K}$, member 2 & Maintenance of uterine quiescence ${ }^{27}$ \\
\hline$K D R$ & 4 & Kinase insert domain receptor & $\begin{array}{l}\text { Some genotypes associated with higher PTB risk among } \\
\text { overweight or obese Caucasian women }{ }^{28} \text {; reduced } \\
\text { expression in gestational hypertension, small for } \\
\text { gestational age, and PTB } 29\end{array}$ \\
\hline KLHL2 & 4 & Kelch-like 2 & Not applicable \\
\hline NAA10 & $\mathrm{X}$ & $\mathrm{N}(\alpha)$-acetyltransferase 10 , NatA catalytic subunit & Not applicable \\
\hline STMN3 & 20 & Stathmin-like 3 & $\begin{array}{l}\text { Decidualization in murine uterus in early pregnancy }{ }^{30} \text {; } \\
\text { peripheral blood gene expression in early pregnancy } \\
\text { associated with PTB }\end{array}$ \\
\hline TMEFF2 & 2 & $\begin{array}{l}\text { Transmembrane protein with EGF-like and two } \\
\text { follistatin-like domains } 2\end{array}$ & Expression in uterine leiomyomas ${ }^{31}$ \\
\hline WDR90 & 16 & WD repeat domain 90 & $\begin{array}{l}\text { Peripheral blood gene expression in early pregnancy } \\
\text { associated with PTB } 25\end{array}$ \\
\hline XPNPEP1 & 10 & $\begin{array}{l}\text { X-prolyl aminopeptidase } \\
\text { (aminopeptidase P) 1, soluble }\end{array}$ & $\begin{array}{l}\text { Peripheral blood gene expression in early pregnancy } \\
\text { associated with PTB } 25\end{array}$ \\
\hline
\end{tabular}

Abbreviations: Chr, chromosome; dbPTB, database for PTB; EGF, epidermal growth factor; PTB, preterm birth. 
Table 4 Genes from preterm birth list 3 identified by either CEU_GIH_YRI or CEU_ASW_MEX evolutionary triangulation lists

\begin{tabular}{|c|c|c|c|}
\hline Gene & Chr. & Gene description & $\begin{array}{l}\text { Other prior association(s) with preterm birth and adverse } \\
\text { pregnancy outcomes }\end{array}$ \\
\hline$A G T$ & 1 & Angiotensinogen & Polymorphisms associated with placental hemorrhage $\mathrm{e}^{32}$ \\
\hline COL4A2 & 13 & Collagen type IV & $\begin{array}{l}\text { Increased expression at decidual interface associated with } \\
\text { preeclampsia } 33\end{array}$ \\
\hline COL4A3 & 2 & Collagen type IV & Neonatal respiratory distress syndrome ${ }^{34}$ \\
\hline COL4A4 & 2 & Collagen type IV & Not applicable \\
\hline CSF2 & 5 & Colony-stimulating factor 2 & Not applicable \\
\hline CYP1A1 & 15 & Cytochrome P4501A1 & $\begin{array}{l}\text { Genotype associated with preterm birth among women exposed } \\
\text { to passive cigarette smoke }\end{array}$ \\
\hline NOS3 & 7 & Endothelial nitric oxide synthases & Not applicable \\
\hline FLT1 & 13 & FMS-like tyrosine kinase 1 & $\begin{array}{l}\text { Genotype associated with spontaneous preterm birth }<34 \text { wk } \\
\text { in African American women } 36\end{array}$ \\
\hline FSHR & 2 & Follicle-stimulating hormone receptor & $\begin{array}{l}\text { Multiple haplotypes, polymorphisms associated with preterm } \\
\text { birth } 24,37\end{array}$ \\
\hline GSTM1 & 1 & Glutathione S-transferase mu 1 & $\begin{array}{l}\text { Genotype associated with preterm birth }{ }^{38} \text { particularly in the } \\
\text { setting of high air pollution }\end{array}$ \\
\hline NOS2 & 17 & Inducible nitric oxide synthases & Fetal genotype associated with prematurity ${ }^{40}$ \\
\hline IL1R2 & 2 & Interleukin 1 receptor 2 & Genotypes modify risk for preterm birth ${ }^{41}$ \\
\hline IL6 & 7 & Interleukin 6 & $\begin{array}{l}\text { Cytokine levels, }{ }^{42} \text { genotype }{ }^{43} \text { associated with preterm birth, } \\
\text { and cervical insufficiency in multiple studies }\end{array}$ \\
\hline IRAK1 & $\mathrm{X}$ & Interleukin 1 receptor-associated kinase 1 & Increases in response to uterine inflammation ${ }^{26,44}$ \\
\hline$K D R$ & 4 & Kinase insert domain receptor & Differential methylation and expression in preeclampsia ${ }^{45}$ \\
\hline PTGDR & 14 & Prostanoid DP receptor & Genotype associated with postcoital associated preterm birth $^{46}$ \\
\hline PRKCA & 17 & Protein kinase $C \alpha$ & $\begin{array}{l}\text { Genotype associated with preterm birth in African American } \\
\text { women } 36\end{array}$ \\
\hline KCNN3 & 1 & $\begin{array}{l}\text { Small conductance calcium-activated } \\
\text { potassium channel } 3\end{array}$ & Maternal $^{47}$ and fetal ${ }^{48}$ genotype associated with preterm birth \\
\hline SP3 & 2 & Specificity protein 3 & $\begin{array}{l}\text { Overexpressed in maternal blood in early pregnancy among } \\
\text { women destined to deliver preterm } 25\end{array}$ \\
\hline TLR10 & 4 & Toll-like receptor 10 & Fetal membrane response to inflammation ${ }^{49}$ \\
\hline
\end{tabular}

Abbreviation: Chr, chromosome.

\section{Comment}

We found that applying evolutionary triangulation analysis to spontaneous PTB provided independent support for multiple genes previously associated with disease in separate genome-wide association and candidate gene studies. Therefore, evolutionary triangulation presents an alternative filtering metric for genetic analyses based on evolutionary history. Multiple identified genes have biologic plausibility for spontaneous PTB and have been previously associated with spontaneous PTB in at least one study, as shown in - Tables $\mathbf{3}$ and $\mathbf{4}$. These genes fall into a variety of broad functional categories and classifications theorized to contribute to a predisposition to spontaneous PTB.

Though multiple genes and pathways were identified, it is notable that both spontaneous PTB gene lists 2 and 3 contained multiple genes within key immune response regulatory pathways. Specifically, the immune response gene ontology framework (GO:0006955) was represented by significant results in both lists 2 and 3. Exposure to (and maternal and fetal response to) inflammation and infection have long been implicated in the pathogenesis of spontaneous PTB. ${ }^{18}$ IL6 and other cytokine gene genotypes, ${ }^{19,20}$ antimicrobial immunity, ${ }^{21}$ and the composition of the vaginal microbiome ${ }^{22}$ are known to vary by race and ethnicity ${ }^{23}$; these factors are hypothesized to contribute to some of the racial disparity in spontaneous PTB. These data provide additional support, at the evolutionary level, for the theory that inflammatory pathways contribute to spontaneous PTB.

Other researchers have used evolutionary approaches to examine the genetic contribution to spontaneous PTB. In 2011, Plunkett et al used a phylogenetic approach to identify candidate genes along the human and human-chimpanzee ancestor lineages. ${ }^{24}$ Eight out of the top 10 SNP differences were found within the follicle-stimulating hormone receptor (FSHR) gene. ${ }^{24}$ Notably, the FSHR gene was on list 3 and was confirmed by our evolutionary triangulation methodology. The FSHR gene was not in the dbPTB and therefore not evaluated as a part of list 2 . 
Our study should be interpreted with several limitations in mind. Evolutionary triangulation and this analysis is limited by the unknown degree of similarity between the selected populations and the non-Hispanic white, Hispanic, and nonHispanic black populations used to generate the spontaneous PTB gene lists we examined. HapMap populations, by design, are generally less diverse in comparison to a random sampling of pregnant women at risk for PTB in the United States. Because of the uncertainty regarding which HapMap populations might best represent the admixed Hispanic and non-Hispanic black populations within the United States, we generated two separate evolutionary triangulation gene lists (CEU_GIH_YRI and CEU_ASW_MEX). It is possible that other combinations of HapMap populations may more appropriately estimate the populations studied. The small number of genes analyzed from list 1 likely limited our ability to find statistically significant functional enrichment within this list. However, our focus on gene lists derived from large, multicenter studies or aggregated genetic data minimizes the likelihood that isolated differences local ancestry would limit our results or generalizability. In addition, the literature curation is current for the dbPTB Web site only through July 2013. Recent findings published over the past 4 years could therefore not be included in a systematic manner as they are unavailable online. ${ }^{14,15}$ For that reason, we incorporated the spontaneous PTB gene list by Sheikh et $a{ }^{16}{ }^{16}$ to provide more a contemporaneous gene list.

This study also had several strengths. Application of a novel genetic filtering technique provides additional "verification" of genes or single nucleotide polymorphisms that were marginally significant in previous prematurity studies, and provide a much-needed focus for future investigations given the complex nature of this phenotype. Further, these results present additional proof of concept and suggest that the filtering methodology of evolutionary triangulation may be applied to other disorders of pregnancy that disproportionately affect different populations of women (e.g., preeclampsia or gestational diabetes).

In conclusion, the application of evolutionary triangulation analysis-a novel filtering metric based on evolutionary history-to spontaneous PTB provided independent support for multiple genes previously associated with disease in genomewide association and candidate gene studies. Identification of genes from prior spontaneous PTB genetic association studies through evolutionary triangulation filtering highlights a prioritized list of genes for future investigations of prematurity.

\section{Condensation}

Evolutionary triangulation, a novel bioinformatics approach, provides independent support for multiple genes previously associated with PTB and presents an alternate filtering metric for genetic analyses using evolutionary history.

\section{Note}

This study was presented in part at the Society for Maternal Fetal Medicine's 37th Annual Meeting 2017 (Las Vegas, NV), as an oral concurrent presentation (1/26/17), final abstract ID \#11.

\section{Conflict of Interest}

None.

\section{Acknowledgments}

This work was supported by the March of Dimes Prematurity Research Center Grant (L.M. and S.M.W.) and by NIH 1K23HD067224 (T.A.M.).

\section{References}

1 Smid MC, Stringer EM, Stringer JS. A worldwide epidemic: the problem and challenges of preterm birth in low- and middleincome countries. Am J Perinatol 2016;33(03):276-289

2 Russell RB, Green NS, Steiner CA, et al. Cost of hospitalization for preterm and low birth weight infants in the United States. Pediatrics 2007;120(01):e1-e9

3 Hamilton BE, Martin JA, Osterman MJ, Curtin SC, Matthews TJ. Births: final data for 2014. Natl Vital Stat Rep 2015;64(12):1-64

4 DeFranco EA, Hall ES, Muglia LJ. Racial disparity in previable birth. Am J Obstet Gynecol 2016;214(03):394.e1-394.e7

5 Huang M, Graham BE, Zhang G, et al. Evolutionary triangulation: informing genetic association studies with evolutionary evidence. BioData Min 2016;9:12. Doi: 10.1186/s13040-016-0091-7

6 Zhang W, Ng HW, Shu M, et al. Comparing genetic variants detected in the 1000 genomes project with SNPs determined by the International HapMap Consortium. J Genet 2015;94(04): 731-740

7 International HapMap Consortium. The International HapMap Project. Nature 2003;426(6968):789-796

8 Wang C, Zhan X, Bragg-Gresham J, et al; FUSION Study. Ancestry estimation and control of population stratification for sequencebased association studies. Nat Genet 2014;46(04):409-415

9 Altshuler DM, Gibbs RA, Peltonen L, et al; International HapMap 3 Consortium. Integrating common and rare genetic variation in diverse human populations. Nature 2010;467(7311):52-58

10 Bhatia G, Patterson N, Sankararaman S, Price AL. Estimating and interpreting FST: the impact of rare variants. Genome Res 2013; 23(09):1514-1521

11 Elhaik E. Empirical distributions of F(ST) from large-scale human polymorphism data. PLoS One 2012;7(11):e49837. Doi: 10.1371/ journal.pone.0049837

12 Cockerham CC, Weir BS. Covariances of relatives stemming from a population undergoing mixed self and random mating. Biometrics 1984;40(01):157-164

13 Zhang H, Baldwin DA, Bukowski RK, et al; Eunice Kennedy Shriver National Institute of Child Health and Human Development (NICHD) Genomic and Proteomic Network for Preterm Birth Research (GPN-PBR). A genome-wide association study of early spontaneous preterm delivery. Genet Epidemiol 2015;39(03): 217-226

14 Uzun A, Laliberte A, Parker J, et al. dbPTB: a database for preterm birth. Database (Oxford) 2012;2012:bar069. Doi: 10.1093/database/bar069

15 Uzun A, Sharma S, Padbury J. A bioinformatics approach to preterm birth. Am J Reprod Immunol 2012;67(04):273-277

16 Sheikh IA, Ahmad E, Jamal MS, et al. Spontaneous preterm birth and single nucleotide gene polymorphisms: a recent update. BMC Genomics 2016;17(Suppl 9):759. Doi: 10.1186/s12864-016-3089-0

17 Szklarczyk D, Franceschini A, Wyder S, et al. STRING v10: proteinprotein interaction networks, integrated over the tree of life. Nucleic Acids Res 2015;43(Database issue):D447-D452

18 Menon R, Fortunato SJ. Infection and the role of inflammation in preterm premature rupture of the membranes. Best Pract Res Clin Obstet Gynaecol 2007;21(03):467-478 
19 Wu W, Clark EA, Stoddard GJ, et al. Effect of interleukin-6 polymorphism on risk of preterm birth within population strata: a metaanalysis. BMC Genet 2013;14:30. Doi: 10.1186/1471-2156-14-30

20 Nguyen DP, Genc M, Vardhana S, Babula O, Onderdonk A, Witkin SS. Ethnic differences of polymorphisms in cytokine and innate immune system genes in pregnant women. Obstet Gynecol 2004; 104(02):293-300

21 Jaffe S, Normand N, Jayaram A, et al. Unique variation in genetic selection among black North American women and its potential influence on pregnancy outcome. Med Hypotheses 2013;81(05): 919-922

22 Fettweis JM, Brooks JP, Serrano MG, et al; Vaginal Microbiome Consortium. Differences in vaginal microbiome in African American women versus women of European ancestry. Microbiology 2014;160(Pt 10):2272-2282

23 Menon R, Dunlop AL, Kramer MR, Fortunato SJ, Hogue CJ. An overview of racial disparities in preterm birth rates: caused by infection or inflammatory response? Acta Obstet Gynecol Scand 2011;90(12):1325-1331

24 Plunkett J, Doniger S, Orabona G, et al. An evolutionary genomic approach to identify genes involved in human birth timing. PLoS Genet 2011;7(04):e1001365. Doi: 10.1371/journal.pgen.1001365

25 Enquobahrie DA, Williams MA, Qiu C, et al. Early pregnancy peripheral blood gene expression and risk of preterm delivery: a nested case control study. BMC Pregnancy Childbirth 2009;9:56. Doi: 10.1186/1471-2393-9-56

26 Lyttle B, Chai J, Gonzalez JM, Xu H, Sammel M, Elovitz MA. The negative regulators of the host immune response: an unexplored pathway in preterm birth. Am J Obstet Gynecol 2009;201(03): 284.e1-284.e7

27 Buxton IL, Singer CA, Tichenor JN. Expression of stretch-activated two-pore potassium channels in human myometrium in pregnancy and labor. PLoS One 2010;5(08):e12372. Doi: 10.1371/ journal.pone.0012372

28 Andraweera PH, Dekker GA, Thompson SD, North RA, McCowan LM, Roberts CT; SCOPE Consortium. The interaction between the maternal BMI and angiogenic gene polymorphisms associates with the risk of spontaneous preterm birth. Mol Hum Reprod 2012;18(09):459-465

29 Andraweera PH, Dekker GA, Laurence JA, Roberts CT. Placental expression of VEGF family mRNA in adverse pregnancy outcomes. Placenta 2012;33(06):467-472

30 Yoshie M, Tamura K, Hara T, Kogo H. Expression of stathmin family genes in the murine uterus during early pregnancy. Mol Reprod Dev 2006;73(02):164-172

31 Wu X, Blanck A, Norstedt G, Sahlin L, Flores-Morales A. Identification of genes with higher expression in human uterine leiomyomas than in the corresponding myometrium. Mol Hum Reprod 2002;8(03):246-254

32 Gargano JW, Holzman CB, Senagore PK, et al. Polymorphisms in thrombophilia and renin-angiotensin system pathways, preterm delivery, and evidence of placental hemorrhage. Am J Obstet Gynecol 2009;201(03):317.e1-317.e9

33 Yong HE, Murthi P, Borg A, et al. Increased decidual mRNA expression levels of candidate maternal pre-eclampsia susceptibility genes are associated with clinical severity. Placenta 2014; 35(02):117-124
34 Haas DM, Lai D, Sharma S, et al. Steroid pathway genes and neonatal respiratory distress after betamethasone use in anticipated preterm birth. Reprod Sci 2016;23(05):680-686

35 Luo YJ, Wen XZ, Ding P, et al. Interaction between maternal passive smoking during pregnancy and CYP1A1 and GSTs polymorphisms on spontaneous preterm delivery. PLoS One 2012;7 (11):e49155. Doi: 10.1371/journal.pone.0049155

36 Frey HA, Stout MJ, Pearson LN, et al. Genetic variation associated with preterm birth in African-American women. Am J Obstet Gynecol 2016;215(02):235.e1-235.e8

37 Chun S, Plunkett J, Teramo K, Muglia LJ, Fay JC. Fine-mapping an association of FSHR with preterm birth in a Finnish population. PLoS One 2013;8(10):e78032. Doi: 10.1371/journal.pone.0078032

38 Suh YJ, Kim YJ, Park H, Park EA, Ha EH. Oxidative stress-related gene interactions with preterm delivery in Korean women. Am J Obstet Gynecol 2008;198(05):541.e1-541.e7

39 Suh YJ, Ha EH, Park H, Kim YJ, Kim H, Hong YC. GSTM1 polymorphism along with PM10 exposure contributes to the risk of preterm delivery. Mutat Res 2008;656(1-2):62-67

40 Gibson CS, MacLennan AH, Dekker GA, et al. Genetic polymorphisms and spontaneous preterm birth. Obstet Gynecol 2007;109 (2 Pt 1):384-391

41 Langmia IM, Apalasamy YD, Omar SZ, Mohamed Z. Interleukin 1 receptor type 2 gene polymorphism is associated with reduced risk of preterm birth. J Matern Fetal Neonatal Med 2016;29(20): 3347-3350

42 Chaemsaithong P, Romero R, Docheva N, et al. Comparison of rapid MMP-8 and interleukin- 6 point-of-care tests to identify intraamniotic inflammation/infection and impending preterm delivery in patients with preterm labor and intact membranes. J Matern Fetal Neonatal Med 2017. Doi: 10.1080/14767058.2017.1281904

43 Sundtoft I, Uldbjerg N, Steffensen R, Sommer S, Christiansen OB. Polymorphisms in genes coding for cytokines, mannose-binding lectin, collagen metabolism and thrombophilia in women with cervical insufficiency. Gynecol Obstet Invest 2016;81(01): $15-22$

44 Zhong X, Jiang YZ, Liu P, et al. Toll-like 4 receptor /NFkB inflammatory/miR-146a pathway contributes to the ART-correlated preterm birth outcome. Oncotarget 2016;7(45):72475-72485

45 Sundrani DP, Reddy US, Joshi AA, et al. Differential placental methylation and expression of VEGF, FLT-1 and KDR genes in human term and preterm preeclampsia. Clin Epigenetics 2013;5 (01):6. Doi: 10.1186/1868-7083-5-6

46 Grisaru-Granovsky S, Altarescu G, Finci S, et al. Prostanoid DP receptor (PTGDR) variants in mothers with post-coital associated preterm births: preliminary observations. J Perinatol 2010;30 (01):33-37

47 Day LJ, Schaa KL, Ryckman KK, et al. Single-nucleotide polymorphisms in the KCNN3 gene associate with preterm birth. Reprod Sci 2011;18(03):286-295

48 Mann PC, Cooper ME, Ryckman KK, et al. Polymorphisms in the fetal progesterone receptor and a calcium-activated potassium channel isoform are associated with preterm birth in an Argentinian population. J Perinatol 2013;33(05):336-340

49 Abrahams VM, Potter JA, Bhat G, Peltier MR, Saade G, Menon R. Bacterial modulation of human fetal membrane Toll-like receptor expression. Am J Reprod Immunol 2013;69(01):33-40 